\title{
Training Assistant for Automotive Engineering through Augmented Reality
}

\author{
Fernando R. Pusda, Francisco F. Valencia, \\ Víctor H. Andaluz and Víctor D. Zambrano \\ Universidad de las Fuerzas Armadas ESPE, Sangolquí-Ecuador \\ \{frpusda, ffvalencia, vhandaluz1,vdzambrano\} eespe.edu.ec
}

\begin{abstract}
This article proposes the development of an augmented reality application for mobile devices with Android OS focused on the visualization and interaction of the user with the components, technical characteristics, location and the processes of disassembly and assembly of engine in a vehicle; facilitating the learning process referring to this automotive system. The application was developed in the graphic engine 3D Unity and the use of Vuforia for the recognition of objects in $3 \mathrm{D}$, being a technological tool that allows vouching the learning in the internal combustion engine, guiding the user and changing the paradigms of the use of physical manuals with the new technological advances as the augmented reality.
\end{abstract}

Keywords: Augmented reality, internal combustion engine, software Unity, application Vuforia.

\section{Introduction}

Industrial processes have evolved fastly, and it is very important to train personnel with specific steps and explicit instructions that guarantee personal safety and the correct use of machines to obtain better performance in production, leading industries to create environments that simulate specific events in purpose of user's capacitation in areas such as firefighter training, mine safety, construction and civil engineering, etc., [1] [2]. Inadequate training and insufficient work experience have been identified as one of the main causes of occupational accidents involving the use of modern machinery and equipment. Many of these occupational accidents could be avoided if operators are adequately trained in the work area. New technological advances have been used widely in different types of industries and even in the training of workers, projecting presentations or explanatory videos [3].

In the automotive industry, technological advances have also been developed, both in processes that the operator must perform and in the training of personnel to improve their quality and efficiency [4]. This sector is strongly influenced by the new tools created such as maintenance assistants, intelligent manuals, assembly guides, and others; reinforcing theoretical knowledge and complementing it with practice through the manipulation and control of equipment to carry out industrial processes [5] [6]. Assem- 
bly process planning uses 3D CAD models to manipulate components in order to improve quality levels in terms of accuracy and reduce production time on workstations [7]. Innovate with 3D visualization technologies in manual tasks, use of tools and equipment in workplaces like automobile assembly lines, increases operator welfare and performance in the automotive field by improving general safety conditions [8].

On recent years, the automotive industry has begun to apply Virtual Reality and Augmented Reality, with the aim, allowing designers and engineers to visualize and modify new prototypes of vehicles and their systems, significantly reducing time and development costs, increasing productivity, efficiency of these processes and resulting in an improvement in the quality of new products [6]. The use of Virtual Reality can be seen in vehicle manufacturers, integrating these concepts in the processes of Induction of New Products (NPI) in the design phase, for 3D digitalization, providing an ideal environment for the analysis of possible modifications on the base design [9] [6]. Augmented Reality has been a great help in the simulation of properties and physical phenomena to which vehicles are subjected, obtaining results quickly and accurately [10]. Although this has benefited overall performance in several industrial applications, only in recent years, that AR based assembly systems have been developed that focus on the process of dynamic and interactive instruction by superimposing digital information and components on a real object [11] [12].

This application seeks breaking paradigms with respect to traditional capacitation and trainings, strengthening and improving the learning process in the different work environments, e.g., automobile assembly, automotive systems manufacturing and repair workshops, among others. Given the complexity of the assembly processes and the identification of vehicle components, the proposed application focuses on providing assistance to the user to visualize detailed information of the internal combustion engine of the vehicle, using AR that gives a more dynamic and interactive learning and offers a virtual training support, which can be implemented in the automotive industry to increase productivity on industrial processes. This work divides on three parts:

I. Components description, details each of the parts that make up the engine of the vehicle, using AR to train the user in the recognition of automotive parts;

II. Virtual assembly and disassembly, it allows to visualize onto the mobile device, the components of the automotive systems, specifically the combustion engine of the vehicle and by means of an intelligent guide that train the operator to interact in the processes of assembly and disassembly of the motive joint;

III. Function simulation, gives a clear idea of the work carried out by different parts of the automotive systems present in the vehicle from 3D simulations shown on the screen of the mobile device, being possible to identify the importance of each mechanism and its precision in the cycles performed by the internal combustion engine.

This article is divided in 6 Sections, including the Introduction. Section 2 describes the architecture of the proposed system; Section 3 describes the unmarked tracking system. Section 4 shows the assembly/disassembly and functioning animation, then Section 5 presents the analysis of the results and finally, the conclusions are detailed in Section 6. 


\section{System Architecture}

The automotive industry has evolved over the years in the area of production, manufacturing and maintenance of vehicles, therefore training for new workers is important in these modern technologies in order to improve the experience and increase the safety of operators in industrial processes, using training tools didactic and interactive simulate real situations in a safe way in the virtual environment.

Hence, this article is oriented to the development of an augmented reality application for training and assistance in the assembly processes of the components of a vehicle on Automotive Engineering, like a visual guide for the operator that provides the relevant information of virtual objects creating an innovative experience.

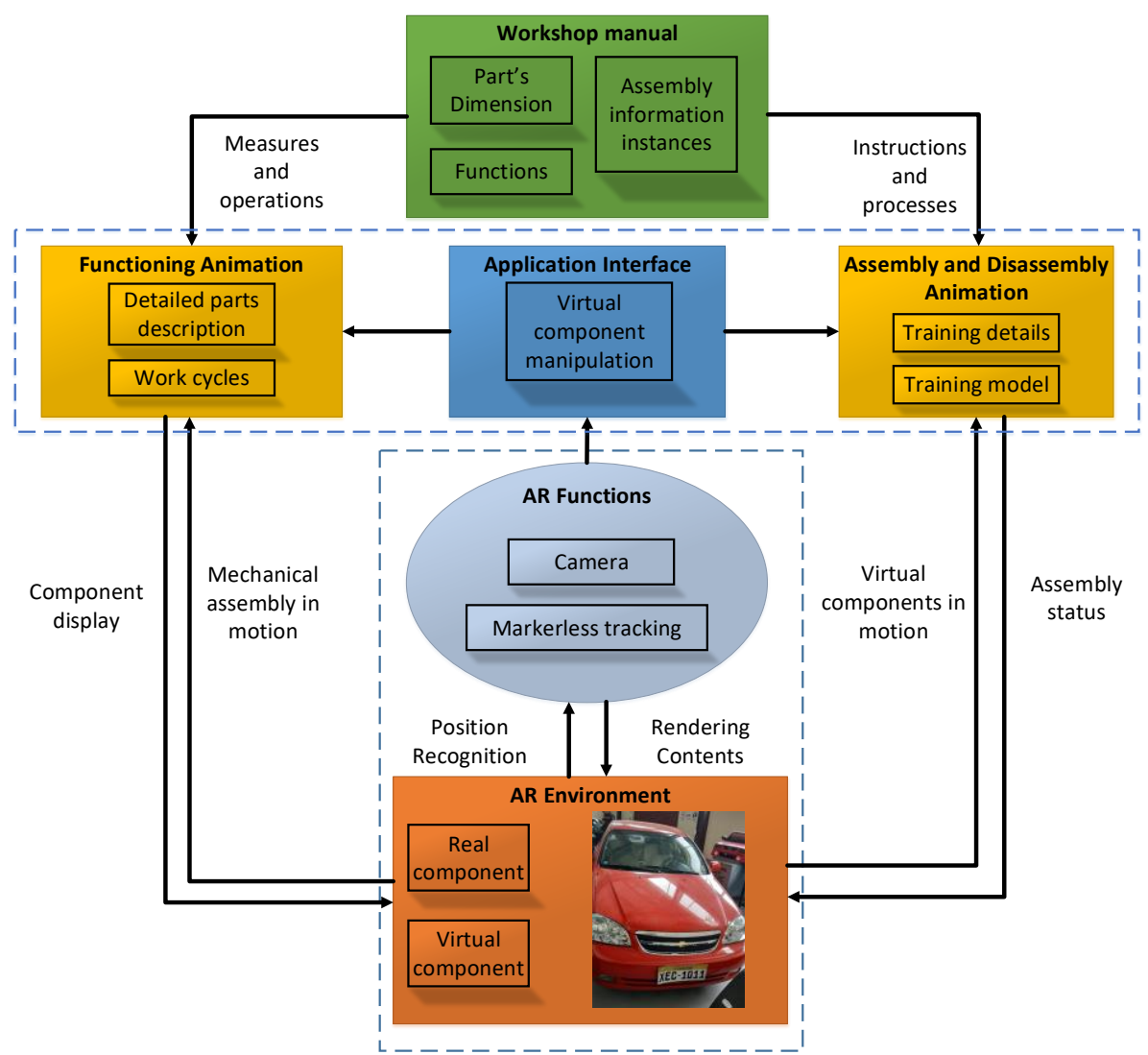

Figure 1: Training system architecture with AR

The Figure 1 shows training system's architecture; for its development the first thing is to obtain the essential information from the vehicle work manual, i.e., the dimensions of the components, the instructions, the assembly and disassembly processes and the operations performed by each part within the automotive system in the work cycle. The application interface allows the user to select between two training areas 
through the mobile device screen, which are System Functioning and Engine Assembly. In the functioning simulation area, it allows the user to see the cycles that are performed in each cylinder of the vehicle engine, e.g., admission, compression, explosion and escape, such as the interaction one by one, the components involved in the operation of the same, also allows to see the detailed description of each the elements that allow the internal combustion engine. In the assembly and disassembly simulation area it is observed step by step this process in an orderly and explanatory way the disassembly of an internal combustion engine, allowing the user to learn the process in a more didactic way, fast and similar to reality.

The Augmented Reality (AR) environment is based on of real and virtual components that are displayed on the mobile device and depending on the option selected in the interface described above will change the movements of digital models, through the functions provided by AR such as the device camera and the recognition pattern focused on the recognition system without marks, the application shows the main menu for the user to access the training.

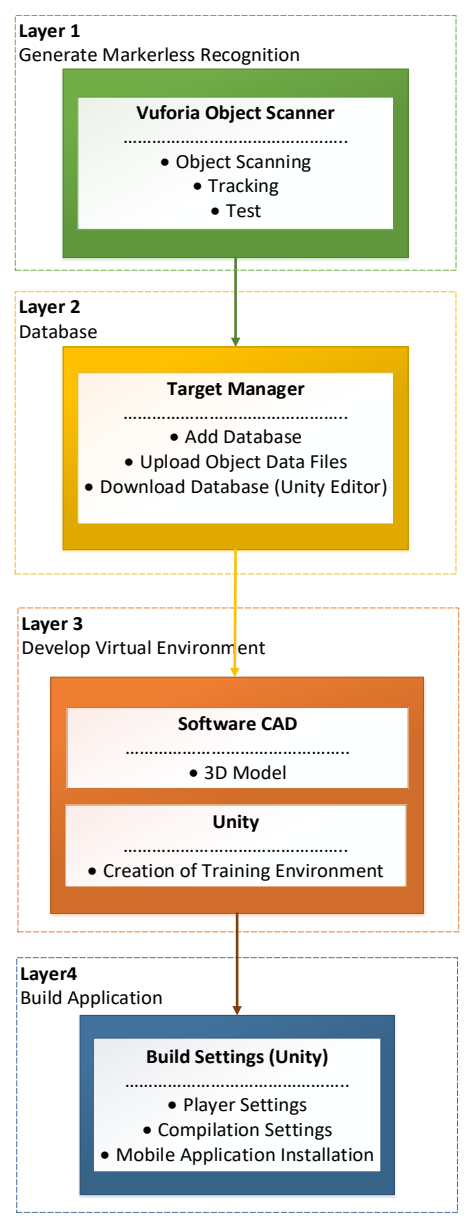

Figure 2: Application layers diagram 
The Figure 2 describes and shows the process for the creation of the application from its initial phase, it is constituted by four general stages and each one defines specific tasks for the development and execution of the training assistant, these are: $i$ ) Marcking less recognition, the $3 \mathrm{D}$ pattern of the object is determined, because the training assistant to be developed proposes the use of a markless tracking system by obtaining characteristic points; ii) Database, allows to save the objects or characteristics to be used through the online portal of Vuforia developers, in the Targets Manager section are added files of 3D objects (*.OD) with compatible characteristics for use in the development of the application; iii) Develop virtual enviroment, refers to the development of the virtual components of the automotive system to be used in the application, in which the 3D elements of the parts and selected parts of the object of study are created through CAD software [13], and also to the animations and tactile controls in Unity; iv) Build Aplication, the presentation parameters such as application orientation, textures, sizes and menu options are configured; also define Android compilation compatible settings by selecting the minimum level of application programming interface (API), as well as application version configuration and Package Name. The created application is transferred to the mobile device for installation and use of the virtual assistant.

\section{Markerless Tracking System}

This system is developed using the Vuforia Object Scanner tool, which enables the use of the mobile device's camera as a scanner to generate a 3D pattern; to begin with, a default objective called "Object Scanning Target" (OST) is selected that defines the position and orientation of the object provided by the Vuforia page. The characteristic region of the target fulfills two functions; it precisely identifies the position of the physical object, and defines the limits of the space of the selected object according to its dimensions.

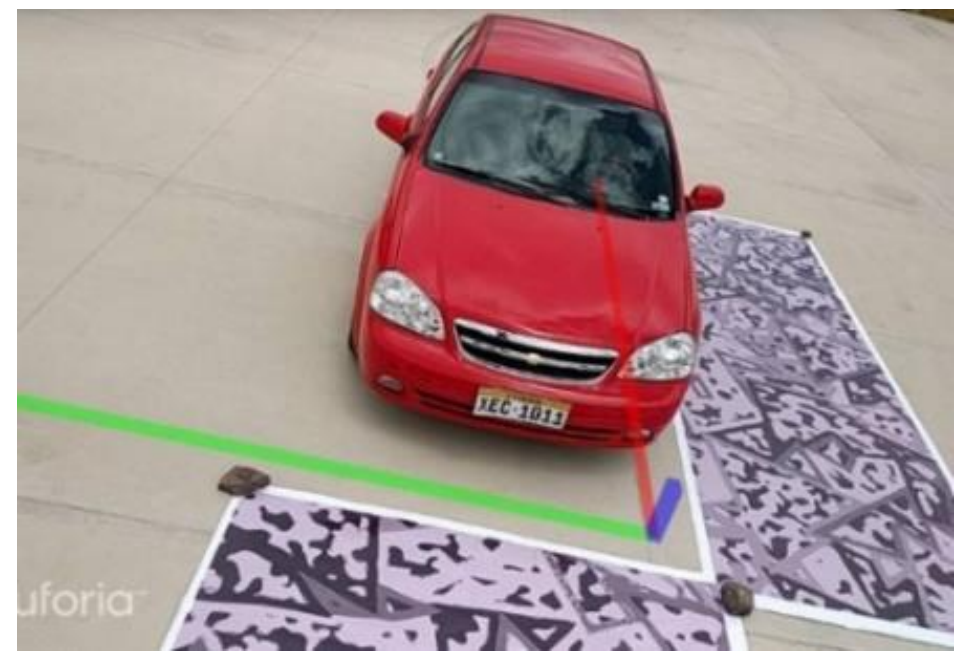

Figure 3: Scanning environment origin 
To initiate the scanning session of the object of study and because of its dimensions, an OST printout was used at a 30:1 magnification scale so that the virtual axes generated from the origin contain the entire vehicle area, as shown in Figure 3. The scanning application allows the capture and recognition of vehicle characteristic points. It is recommended to perform this process with the object of study well aligned with the axes of the OST, in an environment with balanced lighting, placing the object on a light gray background and avoid containing shadows caused by other objects or overexposure brightness.

By moving the camera around the vehicle, a grey virtual dome is displayed and as the characteristic points are captured, the color of the coverage area changes to green. At the Figure 4 the captured characteristic points and the properties of the created marker are shown and the general data of the file is displayed on the summary screen.
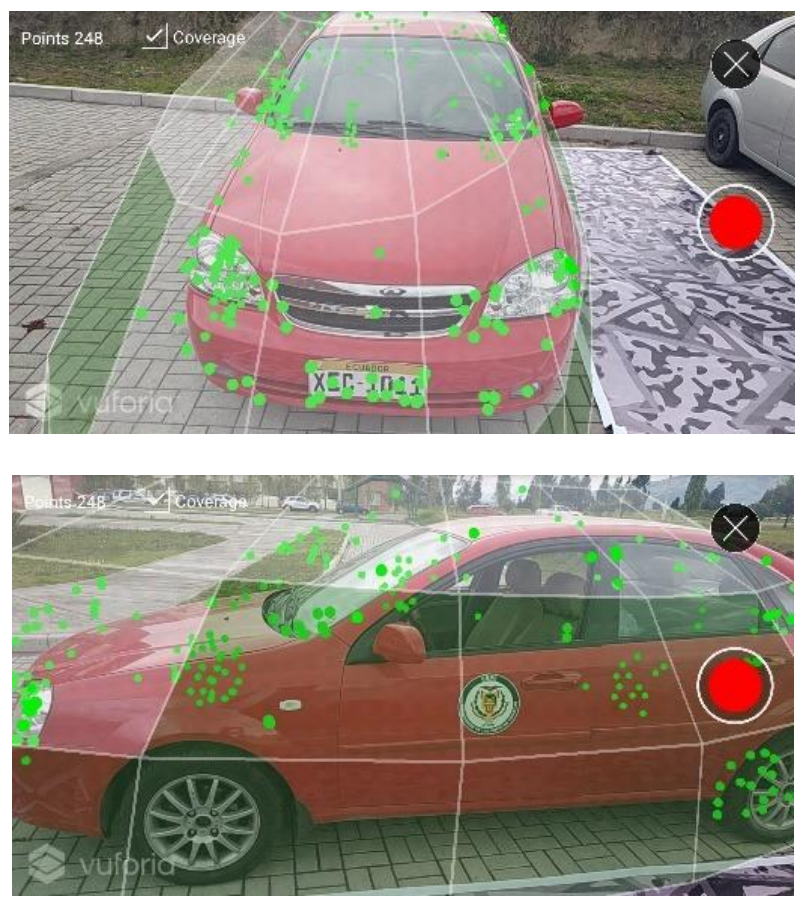

Figure 4: Creation of the pattern 3D

The target manager database can be accessed through the Vuforia developer portal, to configure the object data obtained from the scanning process, creating a license in the License Manager section, being used in Unity for the development of the application.

\section{Assembly/Disassembly and Functioning Animation}

3D models are created with the technical information collected from the vehicle, automotive systems and mechanisms, through a CAD software to be exported to the graphic 
development engine Unity, with the program 3ds Max as shown in Figure 5, creating compatible files (*.FBX) to use them in the virtual environment.

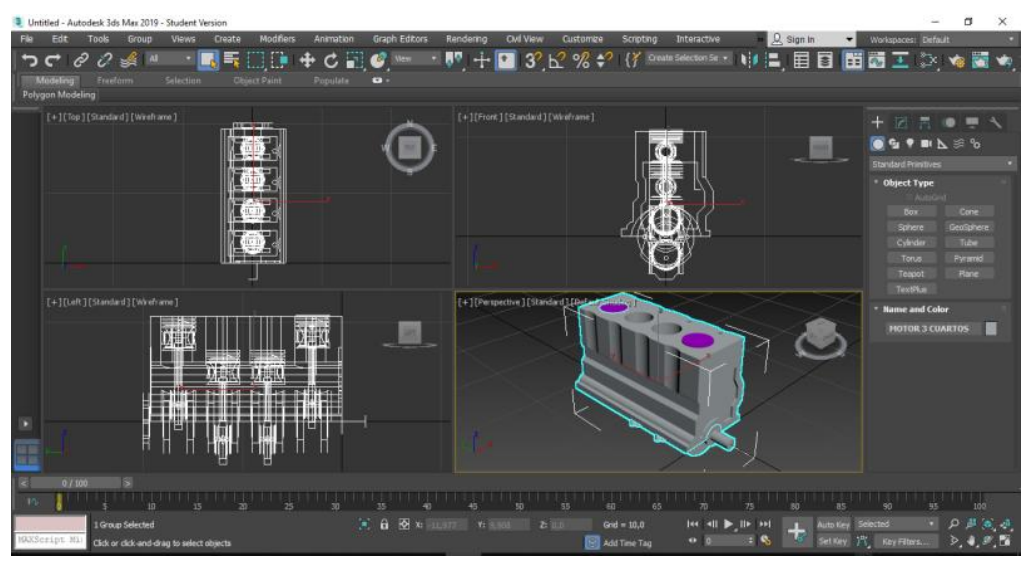

Figure 5: Internal combustion engine in 3ds Max

These models allow to establish animation states based on the flowchart of Figure 6, the initial process is to create a new animation clip and select the components to be used. In this new clip are recorded all the changes required by the scene and distributed through the timeline, taking into account the number of frames per second. A script is developed that allows the control of the states of animation and the game objects.

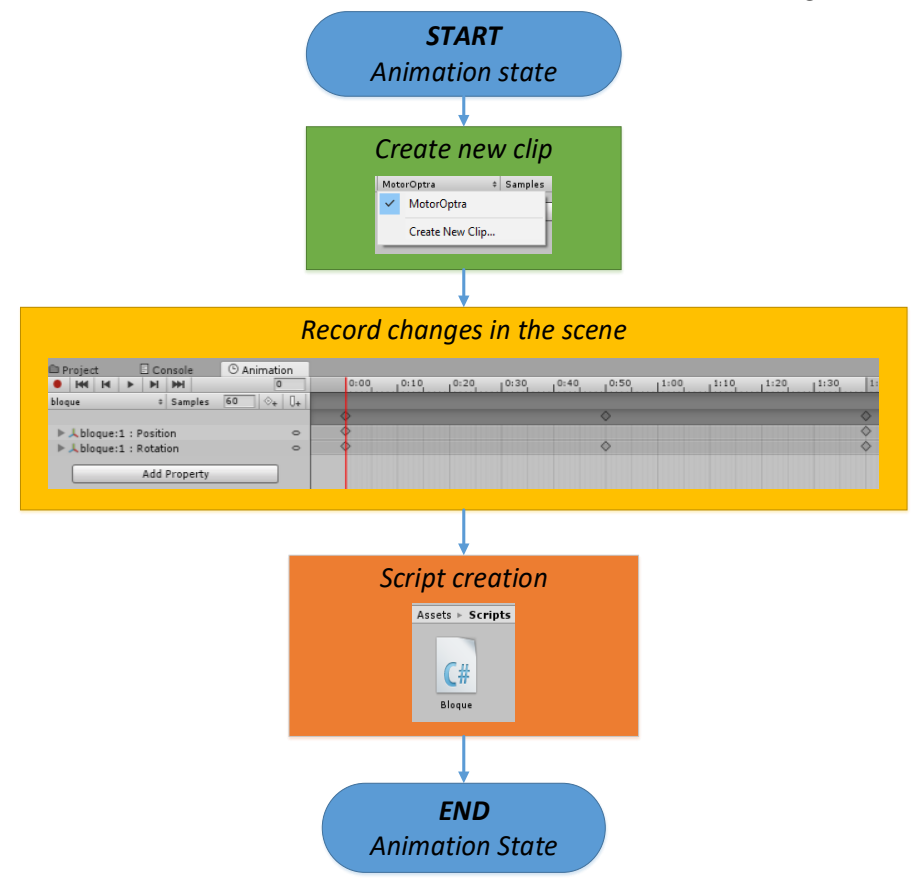

Figure 6: Animation flowchart 
Unity uses the animation panel to create the motion clips of the components and specifies the transformation properties of each piece in mechanical systems; this allows each clip to be integrated into the Animator panel, which uses a graphic system of nodes to represent the animation states and each of them is connected by means of transitions, as shown in the Figure 7.

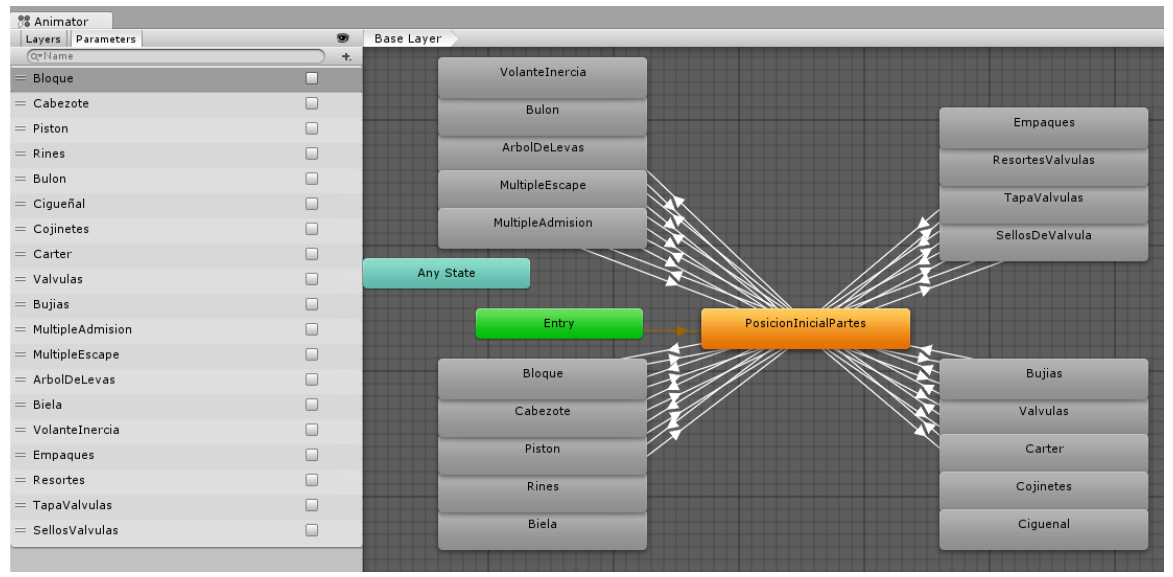

Figure 7: Animation states connected with transitions

Transitions must achieve conditions to generate the environment of interaction with the user by creating parameters, that can be integers, floating, boolean or triggers, with scripts control the parameter's variations, generating changes into the state of the animation. In Figure 8, buttons and scripts are used in Canvas to change scenes, i.e., the procedures for assembly, functioning and technical data are programmed to show the environment of each option by touch controls.
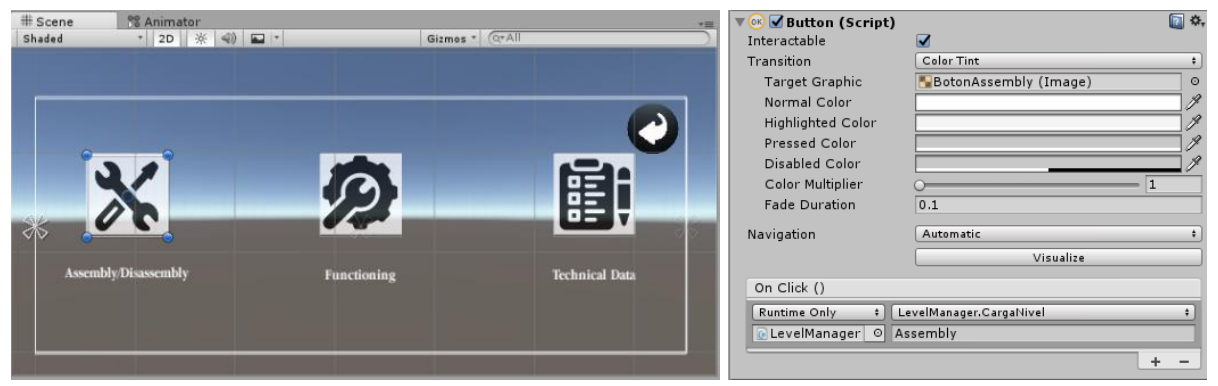

Figure 8: Creation Touch Controls

\section{Analysis and Results}

This section shows the augmented reality performance application focused on user training and assistance, parts recognition automotive system assemblies and their operation. The application can be implemented on industries using this tool to improve the training process and use virtual data to allow innovative assistance. 


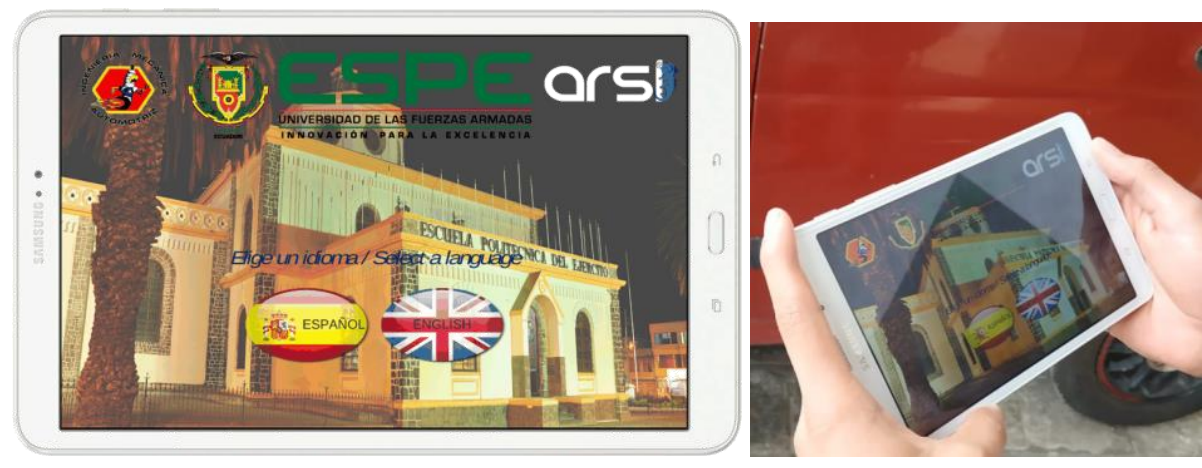

Figure 9: Application language selection

At the beginning of the training assistant, the application first must be installed on the mobile device, the main screen allows you to select the language that is shown in Figure 9.Vehicle recognition is performed by the smartphone camera, allowing user interaction through application functions, e.g., assembly, disassembly, parts recognition and simulation of automotive functioning system.

Figure 10 shows the design of a template AR that allows training assistant to be used with $2 \mathrm{D}$ recognition, to provide knowledge on the assembly and disassembly of an internal combustion engine to the general public without having to be present in the laboratory.

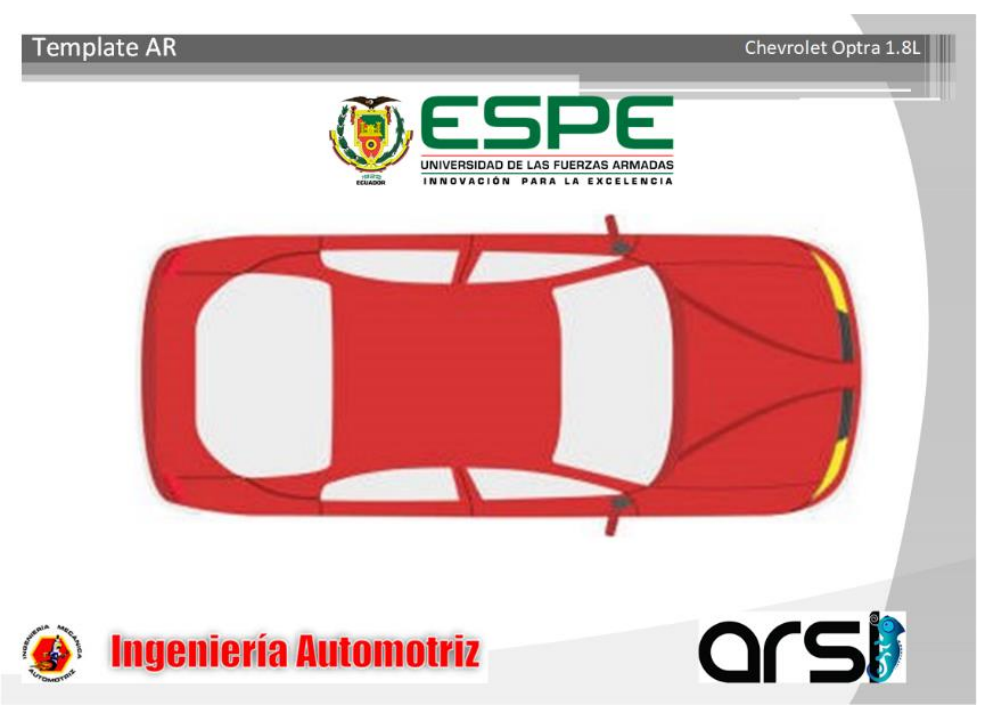

Figure 10: Template 2D

When focused with the camera of the mobile device, the training assistant works normally generate the 3D model of the vehicle and their internal combustion engine parts, as can be seen in Figure 11. 


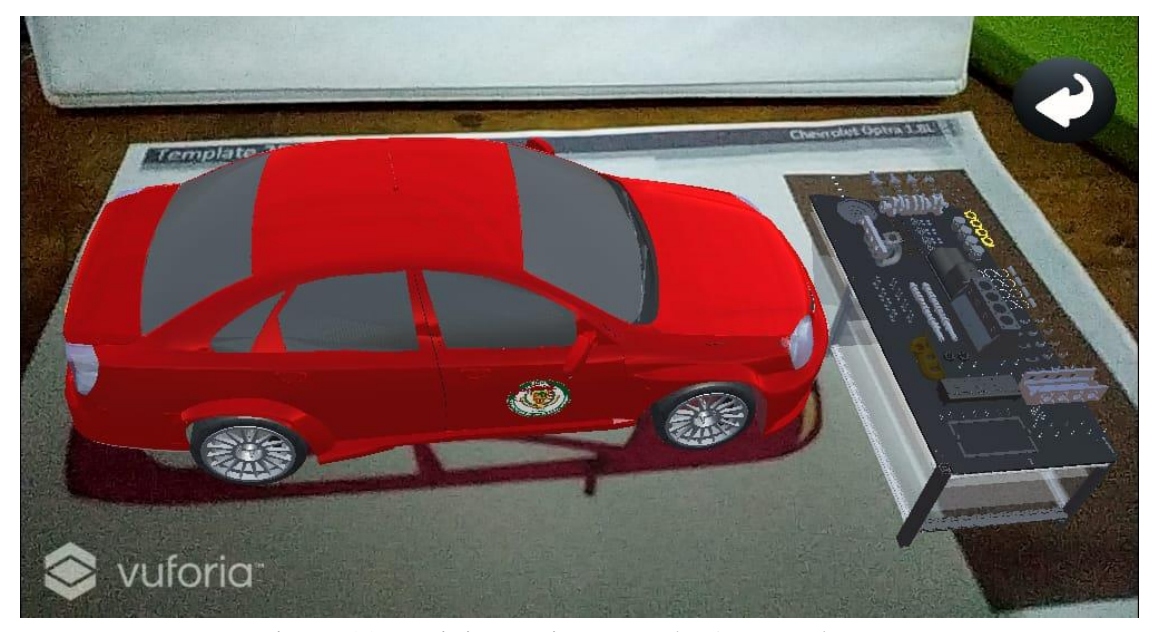

Figure 11: Training assistant on the 2D template

Alternatively, using the assistant in the lab after selecting the language in the main menu should focus on the study vehicle and show the message "Please focus the vehicle" as seen in the Figure 12, until the mobile device camera recognizes the default vehicle; shown on the main menu, leading to the study module selection.

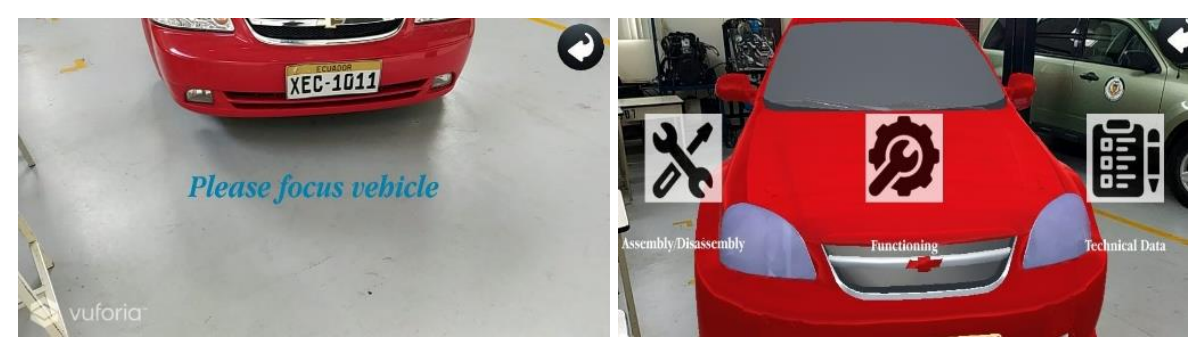

Figure 12: Vehicle recognition

Recognition of parts, this option allows the user to visualize each part of the combustion engine of the vehicle, the same to the detailed technical information of each component as shown in Figure 13.

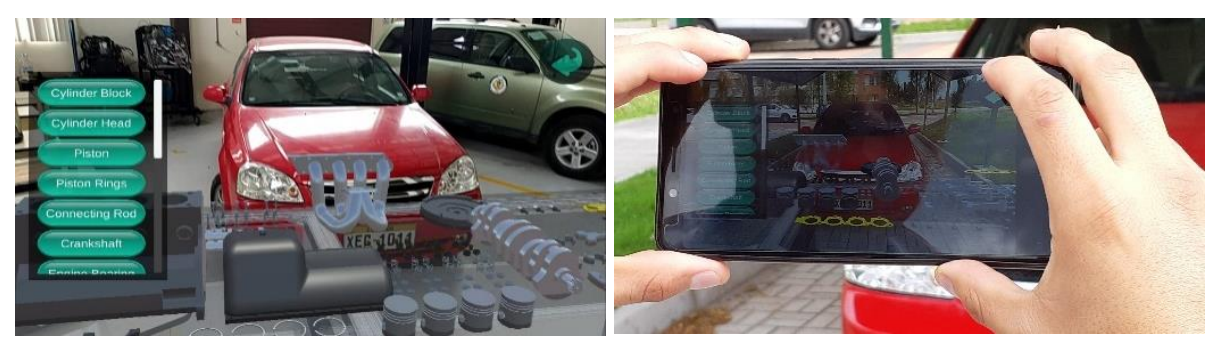

Figure 13: Parts recognition environment 
In Figure 14 the application allows to visualize the description of component using of a text box.

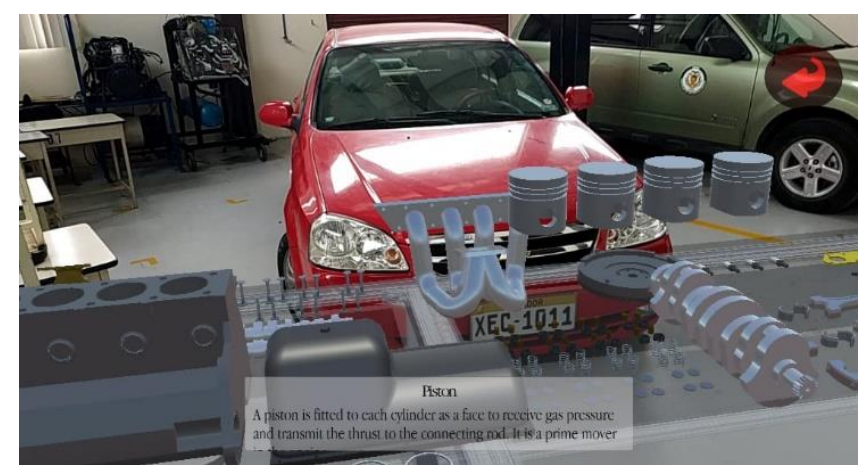

Figure 14: Description of the selected component

Virtual Assembly of Figure 15, assists the user with the procedure of internal combustion assembling and disassembling through the animations and steps described, which are displayed on the device screen.

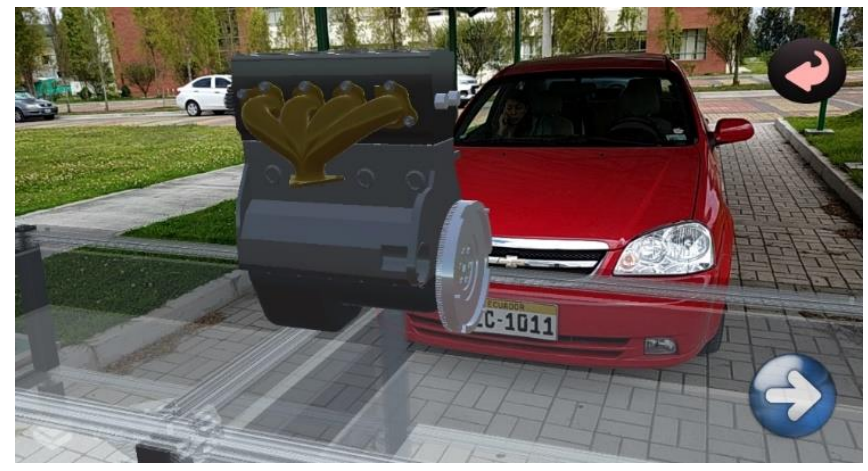

Figure 15: Assembly scene

The simulation of operation is shown in Figure 16 and guided by animations that the user understands in a didactic way the work performed by the mechanical assembly inside the engine.

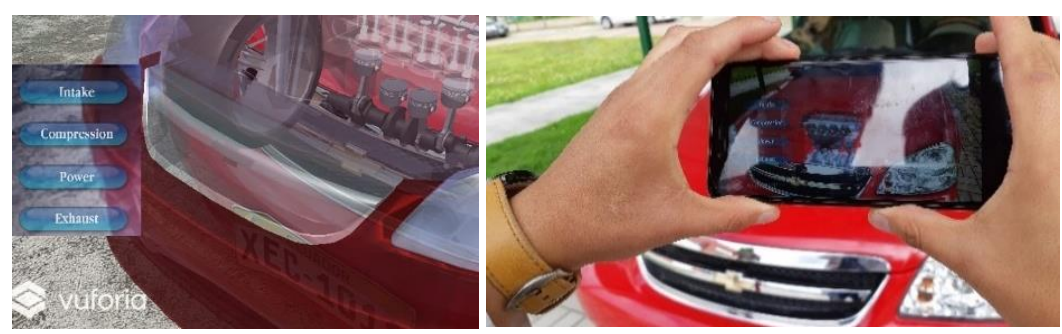

Figure 16: Engine operation and Duty Cycles 
On the vehicle's technical data set is shown three drop-down menus that indicates the engine specifications, fuel need and dimensions, giving the specifications that identify the automobile as shown on the Figure 17.

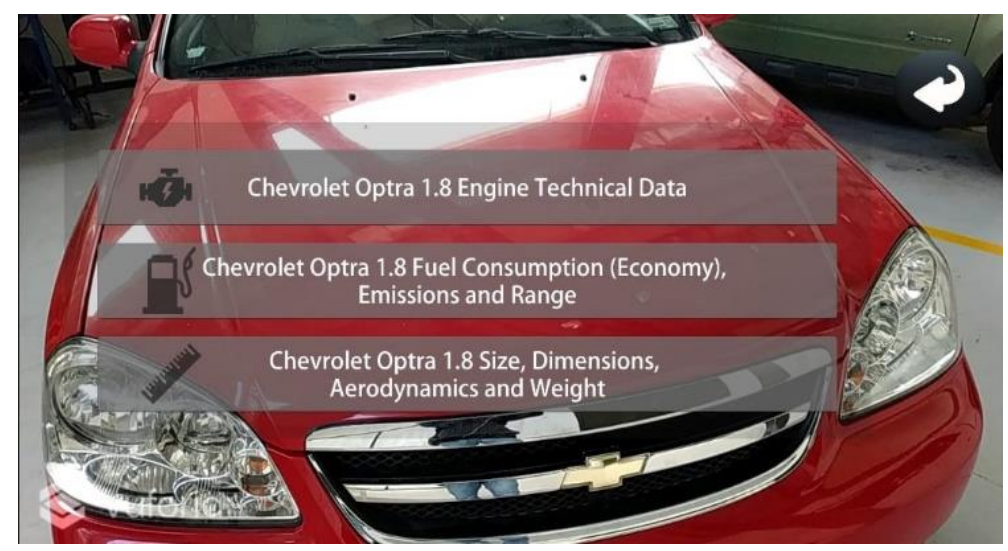

Figure 17: Vehicle's technical data

Finally, a usability test is conducted with two groups of people belonging to automotive engineering: students and teachers, to establish the interest of the training assistant through Augmented Reality [14]. For the first group, it considers ten automotive engineering students of initial levels by the little knowledge in the subject of internal combustion engines, and the assistant is a training guide to reinforce the learners' abilities and the second group included ten teachers of the Universidad de las Fuerzas Armadas ESPE, who made use of the training assistant to evaluate the interaction and familiarization with the application. Table 1 shows the questions posed to both groups, for the valuation of each item the scale from 1 to 5 is used, with 1 being the minimum acceptance and 5 the maximum.

Table 1: Usability evaluation tests

Q1. Is it difficult to get used to the application of augmented reality?

Q2. Do you need specialized support to use this application?

Q3. Do the different training assistant options work properly?

Q4. Do you need to have technical knowledge prior to using the application?

Q5. Is the interaction with the training assistant simple and intuitive?

Q6. Can the virtual training system be implemented in the area of professional education?

Q7. How difficult is the handling of automotive system components in a virtual environment?

Q8. Is induction necessary before using the training assistant?

Q9. Do you find inconsistencies in this training assistant?

Q10. How often would you use the application? 


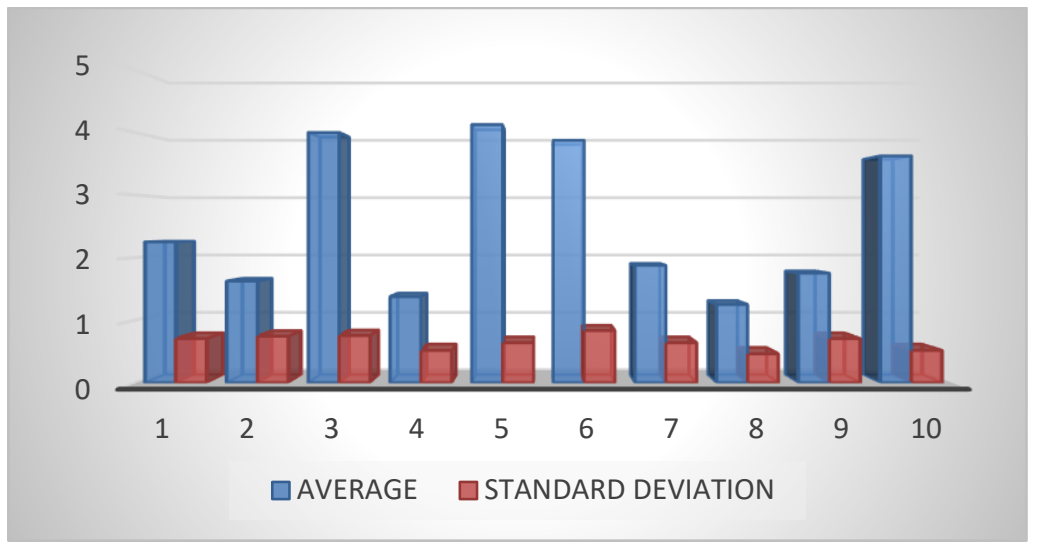

Figure 18: Results of the surveys

The results obtained from the questions posed shown in Figure 18 indicate a high acceptance rate of students and teachers who checked the training assistant.

\section{Conclusion}

The development of applications for training in the automotive industry improves the professional formation processes through the use of augmented reality providing benefits that contribute to recognize and manipulate the elements that compose the automotive systems, guiding the user in the different industrial processes for repair work or assembly of engines, reducing time and resources, improving learning in a safe environment. This work shows acceptation, its accessibility and the development of the Augmented Reality training assistant that provides relevant information and virtual simulations of the processes of assembly, disassembly, recognition and operation of the engine parts in the vehicle, using the markerless tracking system through the screen of a mobile device.

Acknowledgements. The authors would like to thanks to the Corporación Ecuatoriana para el Desarrollo de la Investigación y Academia-CEDIA for the financing given to research, development, and innovation, through the CEPRA projects, espe-cially the project CEPRA-XI-2017-06; Control Coordinado Multi-operador aplicado a un robot Manipulador Aéreo; also to Universidad de las Fuerzas Armadas ESPE, Universidad Técnica de Ambato, Escuela Superior Politécnica de Chimborazo, Uni-versidad Nacional de Chimborazo, and Grupo de Investigación ARSI, for the support to develop this work.

\section{References}

1. M. Rosero, R. Pogo, E. Pruna, V. Andaluz y I. Escobar (2018) Immersive Environment for Training on Industrial Emergencies, Augmented Reality, Virtual Reality, and Computer Graphics, n 10851, pp. 451-466. 
2. D. Tatić y T. Bojan (2017) The application of augmented reality technologies for the improvement of occupational safety in an industrial environment, Computers in Industry, $\mathrm{n}^{\circ} 85$, pp. 1-10.

3. C. J. Turner, W. Hutabarat, J. Oyekan y A. Tiwari (2016) Discrete event simulation and virtual reality use in industry: New opportunities and future trends., IEEE Transactions on Human-Machine Systems, no 46, pp. 882-894.

4. B. Sarupuri, G. A. Lee y M. Billinghurst (2016) An augmented reality guide for assisting forklift operation., IEEE International Symposium on Mixed and Augmented Reality (ISMAR-Adjunct). IEEE 2016, pp. 59-60.

5. J. P. Lima, R. Roberto, F. Simões, M. Almeida, L. Figueiredo, J. M. TeixeiAR y V. Teichrieb (2017) Markerless tracking system for augmented reality in the automotive industry, Expert Systems with Applications, n 82, pp. 100-114.

6. J. S. Ortiz, J. S. Sánchez, P. M. Velasco, W. X. Quevedo, C. P. Carvajal, V. Morales, P. X. Ayala y V. H. Andaluz (2018) Virtual training for industrial automation processes through pneumatic controls, International Conference on Augmented Reality, Virtual Reality and Computer Graphics, pp. 516-532.

7. C. J. Chen, J. Hong y S. F. Wang (2015) Automated positioning of 3D virtual scene in AR-based assembly and disassembly guiding system., The International Journal of Advanced Manufacturing Technology, nº 76, pp. 753-764.

8. E. Laudante y F. Caputo (2016) Design and Digital Manufacturing: an ergonomic approach for Industry 4.0, Systems\&design: beyond processes and thinking, pp. 922-934.

9. J. S. Ortiz, J. S. Sánchez, P. M. Velasco, C. R. Sánchez, W. X. Quevedo, V. D. Zambrano, O. Arteaga y V. H. Andaluz (2017) Teaching-Learning Process through VR Applied to Automotive Engineering., Proceedings of the 2017 9th International Conference on Education Technology and Computers, pp. 36-40,

10. J. Zhang, Y. T. Sung, H. T. Hou y K. E. Chang (2014) The development and evaluation of an augmented reality-based armillary sphere for astronomical observation instruction., Computers \& Education, nº 73, pp. 178-188.

11. P. Hořejší (2015) Augmented reality system for virtual training of parts assembly., Procedia Engineering 100, pp. 699-706.

12. J. Jetter, J. Eimecke y A. Rese (2018) Augmented reality tools for industrial applications: What are potential key performance indicators and who benefits?, Computers in Human Behavior, $\mathrm{n}^{\circ}$ 87, pp. 18-33.

13. W. X. Quevedo, J. S. Sánchez, O. Arteaga, M. Álvarez, V. D. Zambrano, C. R. Sánchez y V. H. Andaluz (2017) Virtual Reality System for Training in Automotive Mechanics, International Conference on Augmented Reality, Virtual Reality and Computer Graphics, pp. 185-198.

14. V. H. Andaluz, J. S. Sánchez, C. R. Sánchez, W. X. Quevedo, J. Varela, J. L. Morales y G. Cuzco (2018) Multi-user industrial training and education environment, International Conference on Augmented Reality, Virtual Reality and Computer Graphics, pp. 533-546. 